\title{
Research on Management and Policy Measures of Training in Applied Mechanical Innovative Talents
}

\author{
Sui Xiulin ${ }^{1, a}$, Tiequn Duan ${ }^{2, b}$, Yiwen Wang ${ }^{3, c}$ \\ School of Mechanical and Power Engineering Harbin University of Science and Technology \\ Harbin, China \\ a *suixiulin@sina.com, btqduan@126.com, cyiwen0451@yahoo.com.cn
}

Keywords: Mechanical; Innovative talents; Management; Policy measures; security system

\begin{abstract}
The training in applied mechanical innovative talents aims to train a number of high-quality technical personnel in mechanical engineering which with innovative ability and adapt to the needs of economic and social development. In this paper, the talents training for the plan of excellent engineers in mechanical design, manufacturing and automation of Harbin University of Science and Technology is taken as the research object. Management system and policy measures of training in applied mechanical innovative talents is described in the aspects of the organization framework, security system, teaching operation and management system, and the major and typical policy measures for applied mechanical innovative talents are put forward. Cultivating applied mechanical innovative talents is to cultivate "outstanding mechanical engineer quality, quick, innovative, good business", and to achieve the purpose of cultivating the "Engineering", "innovation" talent. The research establishes the foundation for "mechanical excellent engineer education and training programs", and provides guarantee to transport mechanical high-level applied talents for enterprises.
\end{abstract}

\section{Introduction}

The plan of educating and training excellent engineers is the major reform project of "national medium and long-term educational reform and development plan (2010-2020)" and "national long-term talent development planning outline (2010-2020)". And it's also an important measure to promote our country from engineering education nation towards powerful engineering education nation. The Ministry of Education approved the second batch of "The plan of educating and training excellent engineers in Colleges and universities". Our school is one of the national "The plan of educating and training excellent engineers in colleges and universities". The mechanical design, manufacturing and automation, automation Engineer of our school become the second batch disciplines of the plan of educating and training excellent engineers in colleges and universities. In order to implement the spirit of the plan, and active service the national strategy and enterprises demand, a new mechanism for training talents by colleges and universities, enterprises is established, and further develop the role of enterprises in the training of engineering talent. As a result, the students' engineering quality is improved, students' engineering practice ability, ability of engineering design and engineering innovation ability is cultivated. The implementation of plan of training in applied mechanical innovative talents is actively promoted.

Harbin university of Science and Technology officially launched the "plan of mechanical excellent engineers" with Xinya Group of Zhejiang province and Harbin Cinema Equipment Co., Ltd, college of Mechanical and Power Engineering chosen students to participate in the "plan of excellent engineers". On the training program, conducts in-depth exploration of practice base, the students' practical training, students' graduate design and other aspects. Through the implementation of the internship program, in-depth exploration of contact and contradictory the national development, business needs, personnel training and the desire among students, explore the transition culture methods school to company, to 
cultivate "Engineering" and "innovation" talent purpose, to promote the further implementation of the "The plan of educating and training excellent engineers" a fruitful exploration.

\section{Organization and management}

Structure of Organization. In order to ensure the implementation, operation and management of mechanical innovative talents "Excellent Engineers Training Program" and with the help of the unified leadership of the working group of Harbin University of Science and Technology, the leading groups and working group of this program in Harbin University of Science and Technology, and Mechanical Power Engineering Institute were established.

Security System. The discipline of mechanical design, manufacturing and automation is the traditional advantage major in Harbin University of Science and Technology, and it has become one of the largest and most comprehensive strength disciplines. mechanical design, manufacturing and automation was named the first batch of key disciplines of Heilongjiang Province in 2000, on the basis of the key discipline of the former Ministry of machinery. It was named the key profession of Heilongjiang Province in 2005 and 2011, and it was named the national characteristic specialty in 2007.

Currently, the school has a mechanical engineering experimental center and resource sharing of the engineering training center, and it has the total area of about 11000 square meters and its instruments and equipment worth more than 15 million. In order to provide a good experimental training base for applied engineering talents. The Education Department of Heilongjiang Province established "machining with CNC technology training center" about revitalizing the northeast old industrial base in school. At the same time, to ensure the smooth implementation of applied engineering and technical personnel training set of the practical aspects of teaching, the professional has more than 20 teaching practice bases both inside and outside the province, such as Qiqihar Heavy CNC equipment Limited by Share Ltd, Changchun First Automobile Works, Harbin motor factory, Harbin automobile gear factory, Harbin film factory.

Based on the school's professional characteristics, we adhere to the train to meet the actual needs of the electrical industry practicality applied talents as the goal, adhere to the cooperation between schools and enterprises, the reform of the curriculum system, strengthening practice teaching, strengthening the teachers team construction, pay attention to international cooperation and exchange, to cultivate students' Engineering practice ability and innovative consciousness. For the needs of society and business, some preliminary results, which in the "order type" talents training, internship, graduation design, skills training and other aspects of a lot of research work, had been achieved, on the basis of we signed training agreements with Qiqihar Heavy CNC Equipment Co., Ltd., Harbin First Tool Manufacturing Co., Ltd., Harbin Kazakhstan video movie Machinery Co. and other enterprises. It provides a good foundation for the "excellence in engineering education and training programs".

Teaching Operation and Management System. Management committee with participation of the relevant person in charge of enterprises and schools will be set up, which complete set of all the articles of association and daily management and coordinating solve major problems in excellence engineers plan. At the same time, engineering practice teaching steering committee and the academic committee will also be established, which are composed of senior professors and senior engineering and technical personnel and are responsible for formulation of teaching development plans and participate in writing the talent training scheme of excellence engineers. In addition, it is also responsible for the running of theory and practice of innovation projects and reform work. The comprehensive office is responsible for the daily work, which is composed of department of theory teaching, the department of innovation experiment, and department of engineering practice, department of graduation design and department of life management. 
The structure of teaching operation and management system of mechanical design, manufacturing and automation is shown in Figure 1.

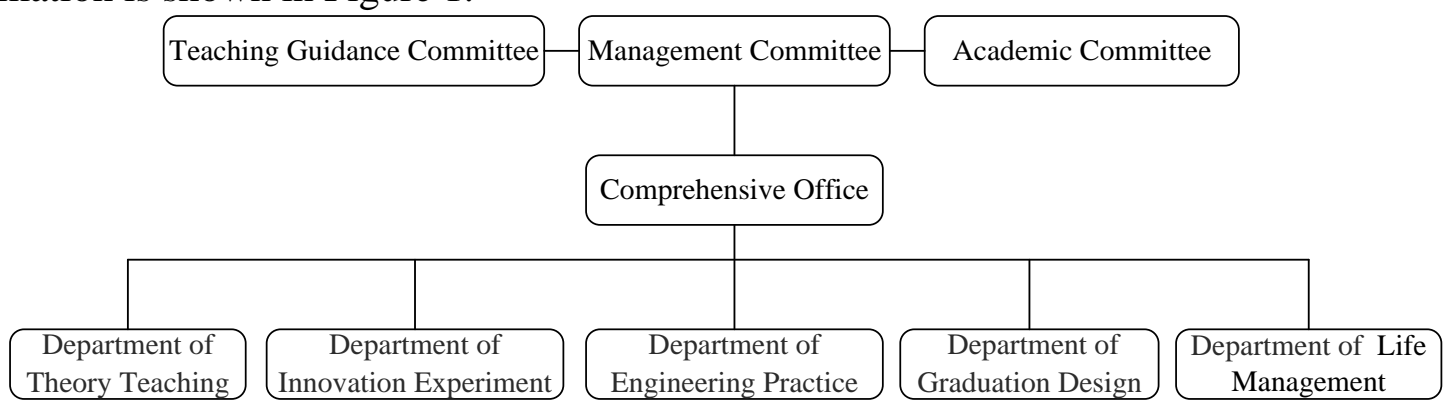

Figure. 1 Structure of teaching operation and management system

\section{Policy measures}

Major Policies and Measures is Introduced by School Level for Excellence. Our school has always been to "a key work in construction of personnel of a new type of higher engineering education training system" as the school of deepening teaching reform, improve the quality of teaching to grasp, to strengthen the teachers troop construction, actively implement the construction funds.

Our school give priority support to the pilot work of education system reform, the "special funds for teaching reform of engineering construction" and "quality engineering" project funds are established; At the same time, the school in Internship, practice, innovation experiment, teaching material construction, graduation design will give corresponding investment and financing, the investment of about 500000 each year. School attaches great importance to education to cultivate excellent engineers work, from teachers of post setting, grants, and title assess, teaching management and so on many aspects of education to cultivate excellent engineers university-enterprise cooperation policy support. The school support college professional direction and dynamic adjustment of teaching content, the compression theory curriculum, reform the teaching methods and the testing method of the course teaching reform, support enterprise college to hire senior engineering and technical personnel and experts in the field to give courses teaching and sent teachers to corporate training and other support for excellence program, college Students, school management and selection and enterprise practice work for the construction of training base, through the establishment of incentive scholarships policies, incentives and funding corresponding to students, arouse the learning enthusiasm of students, provide a guarantee for the smooth implementation of "Excellent Engineer education plan".

\section{Typical Policy Measures is Introduced by College Level for Excellence}

1. For the professional excellence program requirements, supporting for dynamic adjustment of professional direction and teaching content, the compression of theory of curriculum, reform teaching method and testing method of the course teaching reform;

2.College appointed 2-3 teachers to enterprise for training every year, these teachers have accumulated rich experience of engineering practice by the enterprise cooperation projects, enterprises study, for postdoctoral, which some teachers have achieved national recognition of the engineering staff training teachers qualification certificate;

3.2-3 school teachers are selected as experimental class teacher excellence program every year, we offer the favorable policies in Professional Title Evaluation and selection of excellent teachers, teaching workload and other aspects of the teachers;

4. College actively creates conditions to send teachers to participate in the project for excellence in domestic and foreign university of Applied Talents Education Exchange and learning, to participate in the relevant academic conference;

5. Hiring 1-2 domestic and foreign industry as external teachers every year, actively hiring enterprise engineering and technical personnel and industry experts to lecture; 
6. It is supported by college in the field and funds, the student science and technology innovation team is set up, organizing students to participate in various competitions, in order to make excellence students participate in the scientific and technological innovation, self-made experimental equipment and other activities;

7. Vocational skills certification training is actively organized, mechanical design, manufacturing and automation excellence pilot class students receive a certificate of senior technicians CNC machining technology, AutoCAD global certificates and other qualifications through vocational skills certification training.

8. Encouraging the close cooperation between professional and corporate, college built more than 20 teaching practice base, in order to provide a guarantee for the smooth implementation of the excellent engineers education training plan.

\section{Summary}

In order to meet the social and company demand for machinery applied creative talents, the professional of mechanical design and manufacturing and its automation of Harbin university of Science And Technology officially launched the "plan of excellent engineers" with Xinya Group of Zhejiang province and Harbin Cinema Equipment Co., Ltd. The leading group and working group of "The plan of educating and training excellent engineers" is established, and the organizational structure, security system, teaching operation and management system of "The plan of educating and training excellent engineers" are set up for its cultivation. At the school level and college level, corresponding policy measures are introduced respectively. The management and policy measures of training in applied mechanical innovative talents of good transition from school to enterprise is explored. The aim of training "Engineering" and "innovation" talents is achieved. A solid foundation of propelling the training in applied mechanical innovative talents is laid.

\section{Acknowledgements}

This research was sponsored by Heilongjiang Province higher education teaching reform $\operatorname{project}(2013)$.

\section{References}

[1] B.D. Rong, L.X. Ju: Journal of Higher Education, Vol. 31(2010) No09, p.56.

[2] H.Y. Bao, Z.Q Liu, H.B.Wang: The development of the western: in middle Journal,( 2011) No02, p.77

[3] M.G. Lai, L.J. Xiong: Outstanding talents cultivation and the reform of Chinese University(Jiang Xi Publications, China 2011), p.157

[4] L.J. Wang, J.H. Li, Y.Q. Lu: Modern education management, Vol. 03(2011) No03, p.72

[5] H.J. Fu, Y. Xin: Experimental Technology and Management, Vol. 28(2011) No11, p.155

[6] S.S. Zeng: Journal of Chang'an University(Social Science Edition), Vol. 13(2011) No01, p.90

[7] X.Q. Kan: Research on the Improvement of Excellent Engineers Education Training Plan Policy in China-View from Stakeholder Theory(Ph.D., Northeastern University, China 2012), p.34

[8] R. Huang, H.P. Zhou, Z.C. Jia and X.S. Jiang: Research in Teaching,Vol.36(2013) No04, p.89

[9] K.N. Wu: Journal of Higher Education,Vol.34(2013) No01, p.11 
[10] Q.S. Tang, Y.H. Yang and Y.Z. Yang: Journal of Chifeng University (Natural Science Edition ), Vol.340(2014) No09, p.162 